\title{
BOMING SOON!
}

\section{The new edition of the popular and clinically oriented user-friendly text...}

Clinical Infectious Disease

Edited by DAVID SCHLOSSBERG SECOND EDITION SOND EDITION

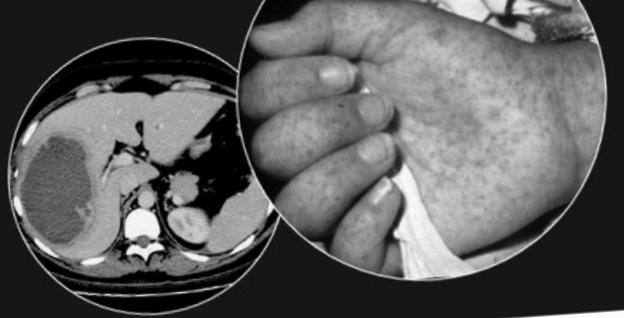

CAMBRIDGE
Medicine
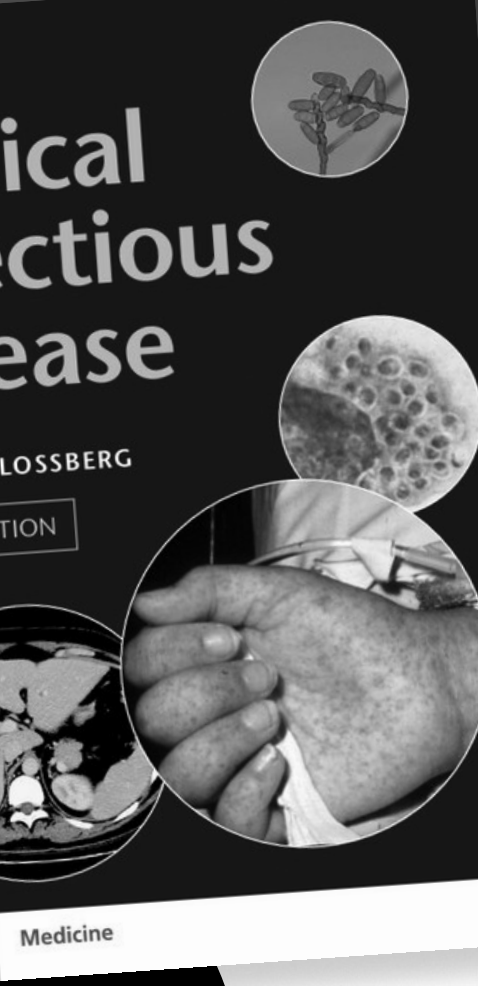

\section{Edited by David Schlossberg, MD}

Temple University, Philadelphia, USA

A fully updated version of this popular, clinically oriented, user-friendly text on infectious disease, with even more helpful graphics, tables, algorithms and images. It is packed full of information on diagnosis, differential diagnosis and therapy. In addition to the traditional organization of organ-system and pathogen-related information, this text also includes clinically helpful sections on the susceptible host (with individual chapters, for example, on the diabetic, the elderly, the injection drug user and the neonate), infections related to travel, infections related to surgery and trauma, nosocomial infection and bioterrorism. Positioned between the available encyclopedic tomes and the smaller pocket guides, this is a convenient, comprehensive, and highly practical reference for all those practicing in infectious diseases as well as internal or general medicine.
- Fully updated and user-friendly
- Abundantly illustrated with high-quality images and tables
- Bridges the gap between the available encyclopedic tomes and smaller pocket guides

\section{PRE-ORDER NOW AND SAVE 20\%}

Hardback | 1608 pages | 114 b/w illus | 236 color illus | 522 tables $\mathbf{9 7 8 1 1 0 7 0 3 8 9 1 2 ~ | ~ C o m i n g ~ M a y ~} 2015$

Pre-order now and save $20 \%$ off the list price!

For more details, including table of contents, list of contributors, and price, visit www.cambridge.org and follow instructions here to get a $\mathbf{2 0} \%$ discount off the list price!
Order direct from the publisher by visiting www.cambridge.org or calling toll free at 1-800-872-7423 and use discount code Schloss20 to save 20\%. (Offer expires $7 / 31 / 2015$.) 


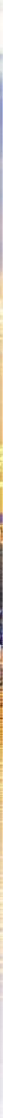

October 7-11 - San Diego, CA • www.idweek.org

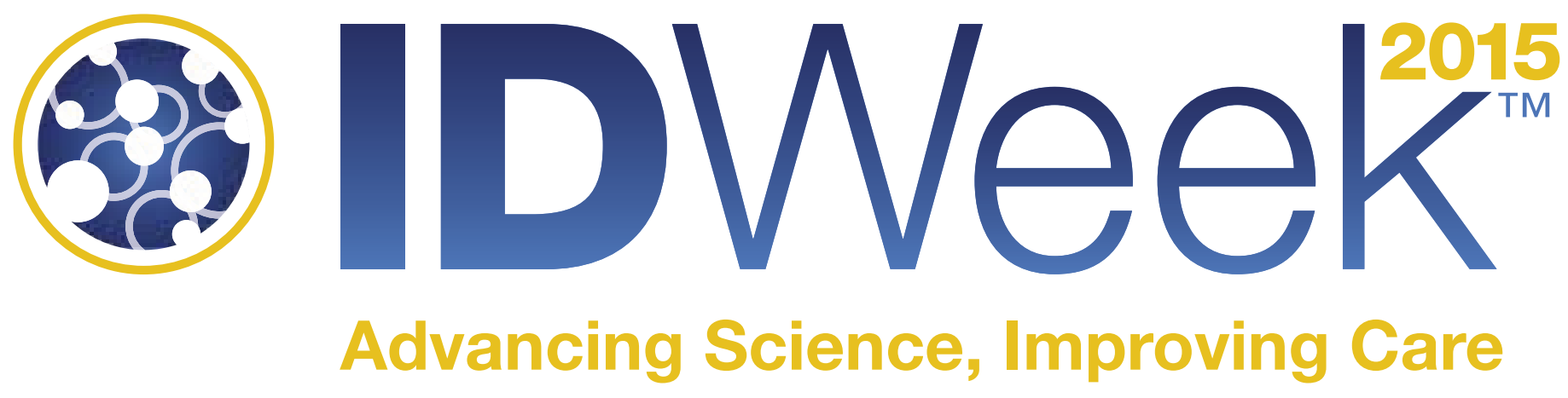

Members Register Now

Registration Open to All - April 14
Accepting Abstracts \& Cases

Deadline 5 p.m. EDT on May 21

Travel Awards and Grants Available

\section{A JOINT MEETING OF}

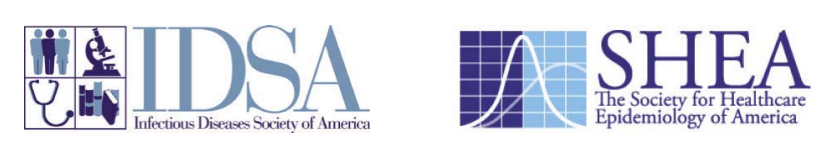

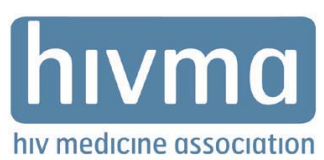

hıv medicıne association

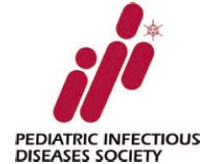


CAMBRIDGE لصRNALS

\section{Cambridge Journals}

\section{$1770-2011$ \\ Over 220 titles \\ From Volume 1}

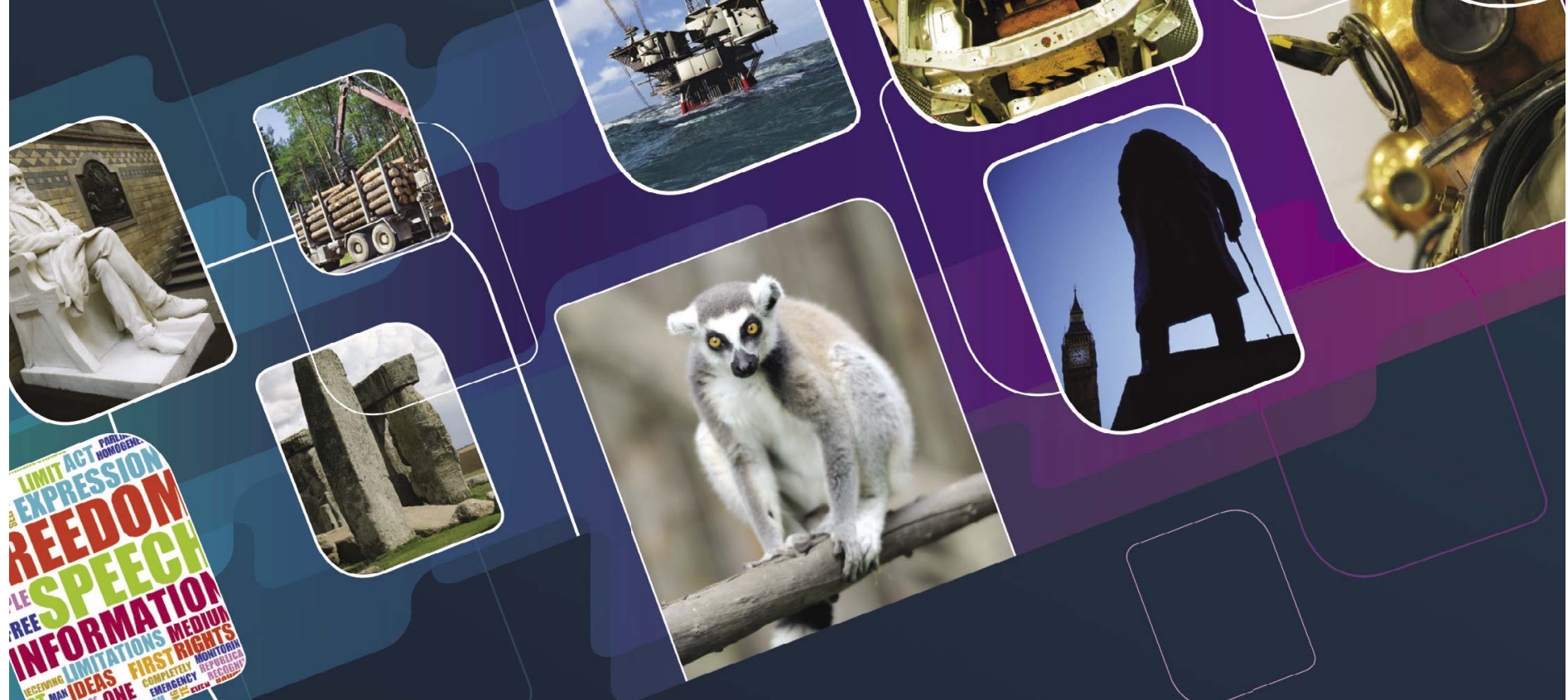

